\title{
Direct Observation via In Situ Heated Stage EBSD Analysis of Recrystallization of Phosphorous Deoxidised Copper in Unstrained and Strained Conditions
}

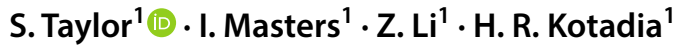

Received: 11 June 2019 / Accepted: 1 October 2019 / Published online: 17 October 2019

(c) The Author(s) 2019

\begin{abstract}
Recrystallization of phosphorous deoxidised copper used for strength critical applications at elevated temperatures was investigated by means of in situ heated stage EBSD analysis using a Gatan Murano heated stage mounted within a Carl Zeiss Sigma FEGSEM electron microscope. The influence of applied strain as the result of deformation within a Nakajima test as an analogue for industrial forming on the recrystallization temperature was investigated, the impact of increased heating rates on microstructural evolution was also investigated. Inverse pole figure plots combined with regions of reduction in local misorientations and variations in geometrically necessary dislocations were used to establish the point of recrystallization and the recrystallized fraction of the material. Recrystallization was observed to occur at temperatures as low as $130{ }^{\circ} \mathrm{C}$ in highly strained samples compared to around $300{ }^{\circ} \mathrm{C}$ within the annealed samples dependent upon heating rate. Increased heating rates were observed to produce a finer final grain structure but had little effect on presence of $<111>60^{\circ}$ grain twins, which was influenced more by initial material condition.
\end{abstract}

Keywords Copper $\cdot$ Twinning $\cdot$ Electron backscattering diffraction (EBSD) $\cdot$ In situ heated stage $\cdot$ Recrystallization

\section{Introduction}

Industry design specifications are based on material properties either derived experimentally or from supplier's specifications. Important properties such as recrystallization temperature are so heavily dependent on material condition and other external factors that they cannot be accurately quoted for a material. Applied strain leads to a significantly altered microstructure, with increased numbers of dislocations and stored energy within a material; at this point the material is no longer within the suppliers' specification. Elevated operating temperatures in formed parts will then lead to stress release and recrystallization of the material at a temperature lower than specified.

Typically with applied temperature, recovery of a material initiates prior to any recrystallization, for complete recovery to occur there must be some light deformation to the microstructure to provide sufficient energy for this

S. Taylor

scott.taylor.1@warwick.ac.uk

1 WMG, University of Warwick, Coventry CV4 7AL, UK process [1]. If a material has been sufficiently strained so that it is heavily work hardened then it may undergo recrystallization with little or no recovery occurring [2]. A greater understanding of the initiation of recrystallization within as received annealed material in comparison to strained material is required to improve the industrial design process.

Grain twins are an important microstructural feature of fcc metals such as copper; fcc metals already deform freely via slip planes and twins offer another deformation mechanism by acting as regions to accommodate deformation arising from recrystallization [3]. Various studies have looked at the influence of grain twins on the resultant material texture $[4,5]$, grain boundary distribution $[6,7]$ and grain orientation $[8,9]$. Studies on the recrystallization of heavily deformed copper have shown that annealing twins have a significant influence on grain growth, with twins allowing growth to continue when this process has stagnated [10].

Studies have investigated the recrystallization of various grades of copper, using both in-situ and post facto analysis [11-13]. Cold drawn copper wire with a $38 \%$ reduction was observed to recrystallize above $200{ }^{\circ} \mathrm{C}$ [14], other studies have reported the initiation of recrystallization at $210{ }^{\circ} \mathrm{C}$ [15]. This study investigates the recrystallization of $\mathrm{Cu}-\mathrm{DHP}$ 
phosphorous deoxidised copper utilized in a strength critical industrial applications under specific conditions.

\section{Materials and Methods}

Pre-rolled commercially available C106-DHP (99.85\% $\mathrm{Cu}, 0.15 \% \mathrm{P}$ ) was used throughout this study. The material was nominally supplied in the annealed condition as $0.5 \mathrm{~mm}$ sheet. The material was investigated in the as received annealed condition directly from supplier and following straining within a biaxial Nakajima test to mimic strains which would be imparted during industrial forming processes. Unstrained samples had a nominal thickness of $0.5 \mathrm{~mm}$. Strained samples were taken from near to the failure region of Nakajima test pieces and had an equivalent strain in the region of $50 \%$. Equivalent strain is based on localised thinning of the material, where $T_{o}$ is original thickness and $\mathrm{T}_{\mathrm{s}}$ is strained thickness.

$\left(\left(\frac{T o}{T S}\right)-1\right) \times 100$

Samples were prepared for EBSD analysis by sectioning and mounting in Bakelite resin; samples were polished mechanically firstly using $\mathrm{SiC}$ grit papers then water based diamond solutions, a final stage polish employing 5\% hydrogen peroxide was employed to provide a light etch and highlight grain boundaries. Following polishing samples were cut from the resin and the surface cleaned with isopropanol using a previously established technique [16].
In situ observations were conducted using a $70^{\circ}$ pretilted Gatan Murano heated stage operating in a Sigma Zeiss FEGSEM with Oxford Aztec software and Symmetry EBSD detector. Scans were conducted with a voltage of $20 \mathrm{keV}$ at $200 \mathrm{~Hz}$ with a $0.5 \mu \mathrm{m}$ step size yielding a total scan time of $70 \mathrm{~s}$ per region. No external fiducial markers were imparted on the surface, existing surface features were employed to account for thermal drift during heating ramps in between EBSD scans. Comparative FSD and SE images were used to ensure the same region of interest was observed throughout. Samples were taken up to a maximum temperature of $550{ }^{\circ} \mathrm{C}$ at rates ranging from 0.01 to $50 \mathrm{C} \mathrm{s}^{-1}$ to look at the influence of heating rate on the material recrystallization.

\section{Results and Discussion}

Previous studies had established the requirement for an initial ramp to $200{ }^{\circ} \mathrm{C}$ to degas materials within the SEM prior to incremental steps to investigate microstructural evolution [16]. As illustrated in Fig. 1 EBSD analysis following this heating showed that strained material (b) had already undergone recrystallization whereas the unstrained material (a) remained unaffected. Local misorientations and grain boundaries remained unaltered within the unstrained material affirming the fact that the grain structure remained unaffected by the heat treatment. IPF maps clearly show a recrystallized structure within the strained material with no evidence of the parent grains remaining; local misorientations were significantly reduced; and a prevalence of $<111>$

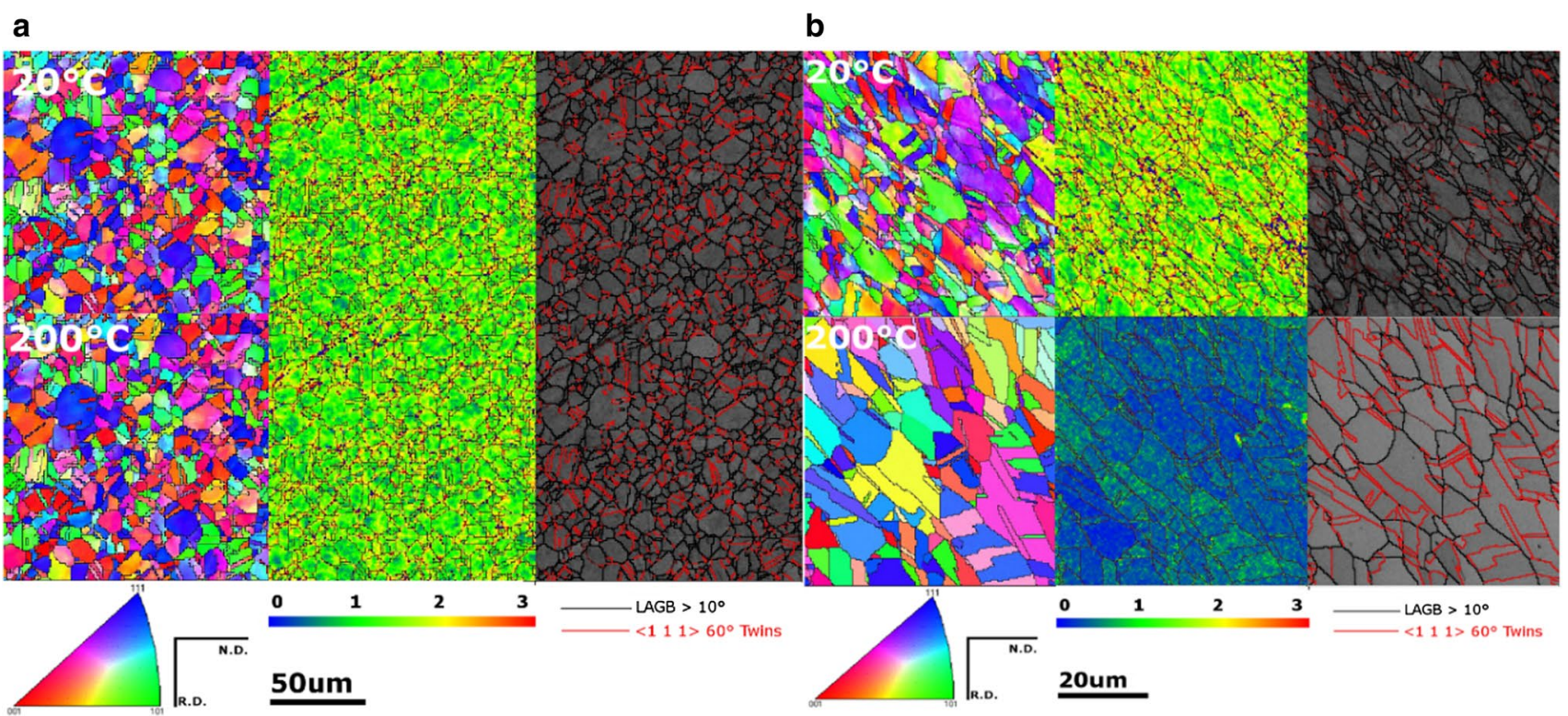

Fig.1 a EBSD, local misorientation and grain boundary angle maps for non-deformed copper at room temperature and after heating to $200{ }^{\circ} \mathrm{C}$. $\mathbf{b}$ EBSD, local misorientation and grain boundary angle maps for strained copper at room temperature and after heating to $200{ }^{\circ} \mathrm{C}$ 
$60^{\circ}$ twin boundaries was evident accounting for around $59 \%$ of the total grain boundaries compared to $10 \%$ for the unstrained material.

Strain energy imparted by deformation is stored within the microstructure in the form of dislocations [17], to understand this unexpected recrystallization the GND (geometrically necessary dislocation) density within both samples were investigated using Oxford channel 5 software. Figure 2 illustrates the GND density maps for both strained and unstrained copper samples, the strained sample having a $4.2 \times 10^{14} / \mathrm{m}^{2}$ compared to $1.6 \times 10^{14} / \mathrm{m}^{2}$ within the unstrained material. This increase in GND density and therefore increased stored energy explains the unexpected recrystallization observed.

Following this discovery degassing was conducted at $110^{\circ} \mathrm{C}$ within incremental steps of $20^{\circ} \mathrm{C}$ at $0.01 \mathrm{C} \mathrm{s}^{-1}$. The resultant IPF orientation maps with corresponding local misorientation maps are given in Fig. 3. Nucleation sites were not always observable with nucleation typically taking place beneath the sample surface [18]. The grain structure remained unchanged at $110^{\circ} \mathrm{C}$, following heating to $130^{\circ} \mathrm{C}$ recrystallization was evident with regions of reduced local misorientations and increased twin boundaries observed. GNU Gimp 2.0 software was used to analyse the number of pixels in regions of reduced local misorientations to give a percentage fraction of recrystallized material.

At $130{ }^{\circ} \mathrm{C}$ approximately $5 \%$ of the sample was recrystallized, incremental steps to $150{ }^{\circ} \mathrm{C}$ increased this to $10 \%$ and at $170{ }^{\circ} \mathrm{C}$ to $10 \%$. Increasing the temperature to $190{ }^{\circ} \mathrm{C}$ increased the recrystallized fraction to approximately $70 \%$ of the structure being recrystallized, $95 \%$ of the sample was recrystallized at $205{ }^{\circ} \mathrm{C}$ and exposure to $225^{\circ} \mathrm{C}$ lead to a fully recrystallized structure illustrated in Fig. 3. Heating was continued up to $400{ }^{\circ} \mathrm{C}$ but no further changes were observed within the microstructure. Regions of recrystallized material were typified by a prevalence of $<111>60^{\circ}$ twin boundaries, at least $50 \%$ of the grain boundaries within recrystallized regions being twin boundaries.

This increase in recrystallization kinetics typified by initiation at lower temperature was expected due to the increased stored energy within the stained samples which is known to be the most influential factor in how quickly copper with recrystallize [17]. With no secondary particles present within the studied material the driving force for recrystallization was purely polygonization, the kinetics of which are dependent upon dislocation density, which is significantly increased within deformed material. Prior to testing the recrystallization temperature was expected to be greater than $200{ }^{\circ} \mathrm{C}$, studies had shown that copper does recrystallize at a lower temperature than this but these studies had been conducted on material which had undergone ECAP processes which lead to massive levels of localised strain and stored energy in [19].

Regions of recrystallized material were typified by reduced local misorientations and by reduced GND density as shown in Figs. 3 and 4. Within regions of reduced GND density the microstructure was typified by $<111>60^{\circ}$ twins illustrated in Fig. 4b. With increased heating GND densities were seen to decrease and the total percentage of $<111>$ $60^{\circ}$ twins to increase proportionally. The fully recrystallized material having a GND density of $0.92 \times 10^{14} / \mathrm{m}^{2}$ and around $65 \%$ of grain boundaries being comprised of $<111>$ $60^{\circ}$ twins. This relationship and the relationship between temperature and recrystallized fraction being illustrated in Fig. 5a, b.

With no evidence of any microstructural evolution within the unstrained material at $200{ }^{\circ} \mathrm{C}$ samples were then degassed at $200{ }^{\circ} \mathrm{C}$ and incremental steps of $25^{\circ} \mathrm{C}$ with a ramp rate of $0.1 \mathrm{C} \mathrm{s}^{-1}$ were applied to observe the initiation of recrystallization. The microstructure remained unchanged up to $400{ }^{\circ} \mathrm{C}$ with local misorientations and grain boundaries remaining the same as the initial condition. On raising the
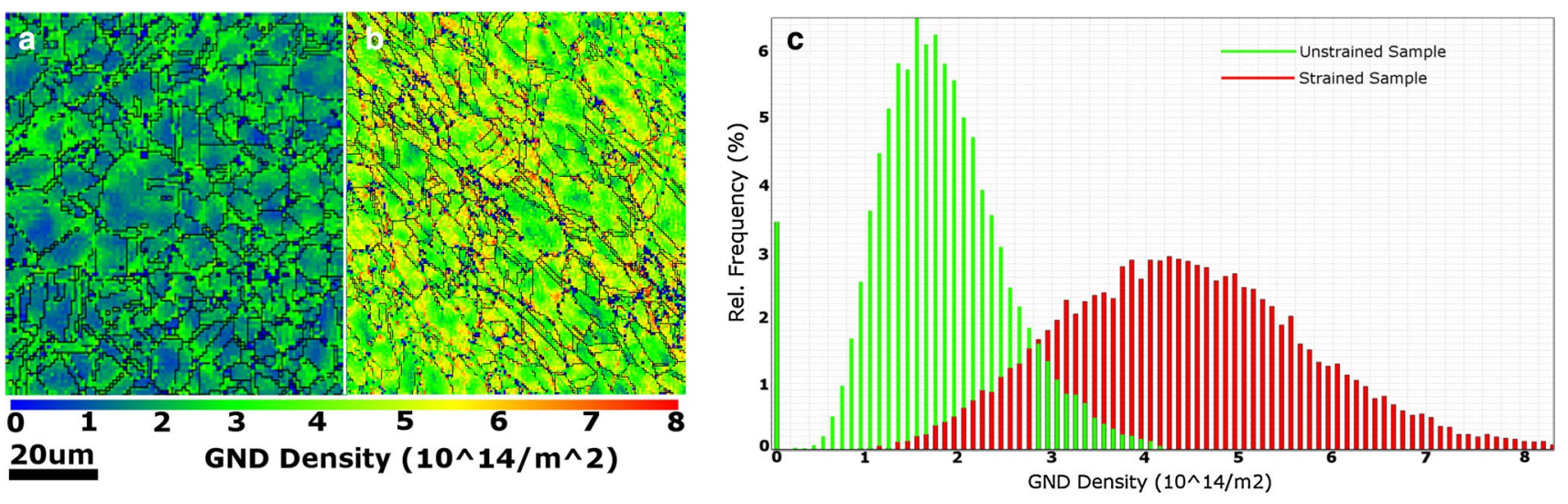

Fig.2 a GND density of unstrained copper, b GND density of strained copper, $\mathbf{c}$ histograms of GND densities of coper in both conditions showing the shift to a higher average within the strained sample 


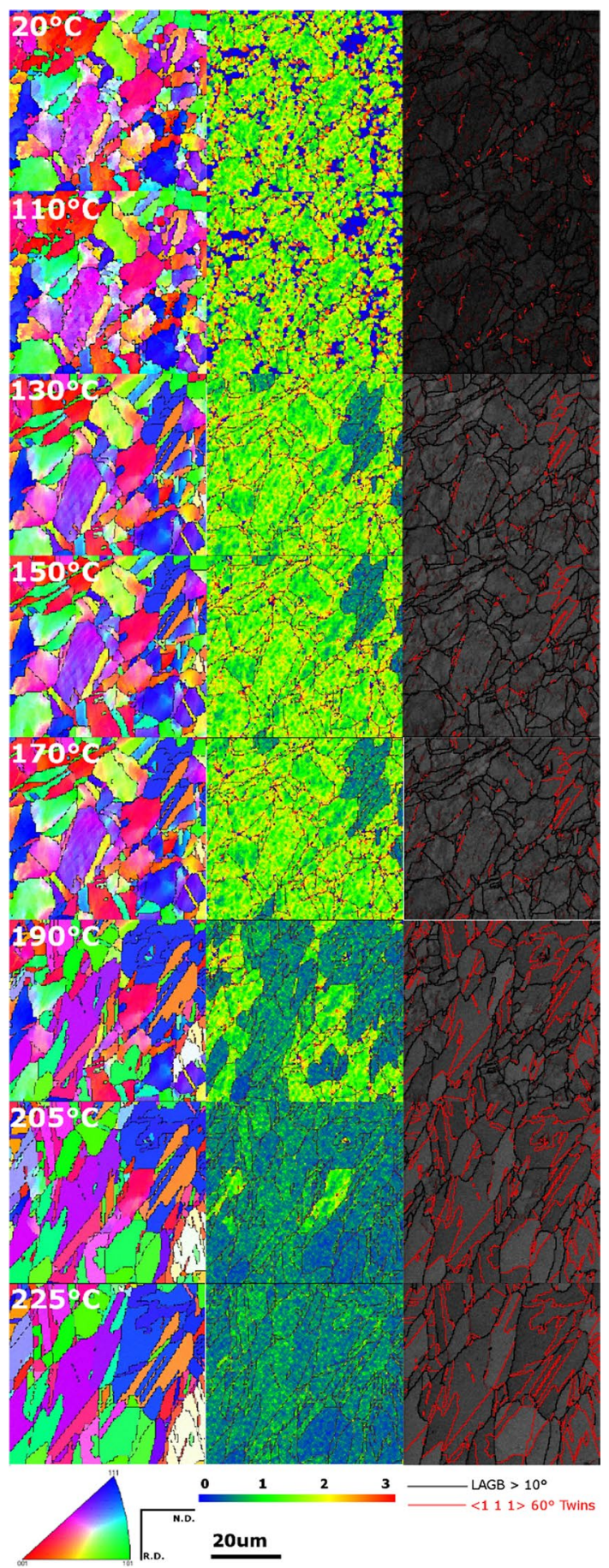

Fig. 3 EBSD, local misorientation and grain boundary angle maps for strained copper showing the material evolution from room temperature, incrementally to $225^{\circ} \mathrm{C}$

temperature to $425{ }^{\circ} \mathrm{C}$ the material was observed to very rapidly recrystallize to a relatively stable microstructure with no evidence of parent grains.

GND density within the sample initially was $2.65 \times 10^{14} / \mathrm{m}^{2}$ this value remained virtually unchanged up to $400{ }^{\circ} \mathrm{C}$ with a slight reduction to $2.44 \times 10^{14} / \mathrm{m}^{2}$ which

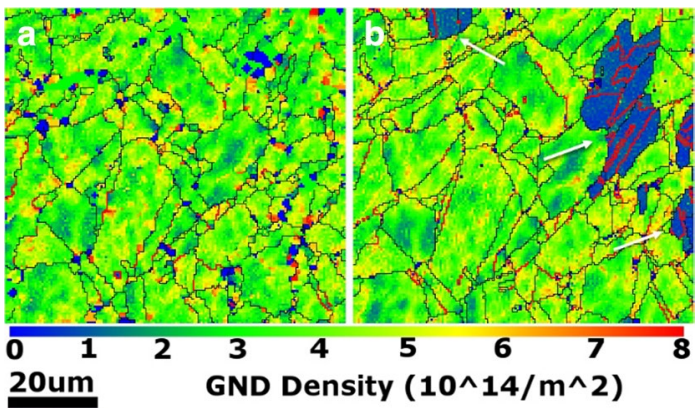

Fig. 4 a GND density map of strained copper at $20{ }^{\circ} \mathrm{C}$, b GND density map of strained copper at $130{ }^{\circ} \mathrm{C}$ with twin boundaries illustrated in red

is indicative of some recovery within the microstructure. Upon heating to $425{ }^{\circ} \mathrm{C}$ the GND density was reduced to $0.85 \times 10^{14} / \mathrm{m}^{2}$ indicating a fully recrystallized structure, following further heating the GND density was seen to remain stable, showing that the recrystallization process had completed.

Due to the speed of recrystallization at these temperatures it was not possible to estimate the percentage fraction at different steps as for the strained sample. Further heating to $500{ }^{\circ} \mathrm{C}$ showed no further evolution of the microstructure, a prolonged dwell at $550{ }^{\circ} \mathrm{C}$ for an hour showed some limited evidence of abnormal grain growth within the microstructure but the driving force for this evolution at this point is very low.

Rapid heating of the material at $25{ }^{\circ} \mathrm{C} \mathrm{s}^{-1}$ to $500{ }^{\circ} \mathrm{C}$ lead to a fine microstructure with an average grain diameter of $16 \mu \mathrm{m}$, and approximately $70 \%$ of the grain boundaries comprising of $<111>60^{\circ}$ twins as shown in Fig. 6a. Heating of the material at a lower rate of $0.1 \mathrm{C} \mathrm{s}^{-1}$ to the same temperature produced a much coarser microstructure with average diameters of $65 \mu \mathrm{m}$, the greater length of time and slower rate of heating allowing for greater recovery prior to recrystallization and also subsequent grain coalescence and growth. Following heating, grain boundaries were observed to be comprised of approximately $70 \%<111>60^{\circ}$ twins as seen in the material heated rapidly.

Samples of strained material were exposed to identical heating rates and the same pattern was observed, slow heating at $0.1 \mathrm{C} \mathrm{s}^{-1}$ lead to a coarser $51 \mu \mathrm{m}$ average diameter microstructure compared to $9 \mu \mathrm{m}$ average in the rapidly heated material shown in Fig. 6b. The microstructure was seen to comprise of approximately $60 \%<111>60^{\circ}$ twins for both heating rates. The finer resultant microstructure of that material is as expected due to the greater stored energy within grain boundaries and dislocations following straining prior to heating. It should be noted that some of the changes observed may be surface effects, however previous studies have shown good correlation between in situ EBSD and bulk 

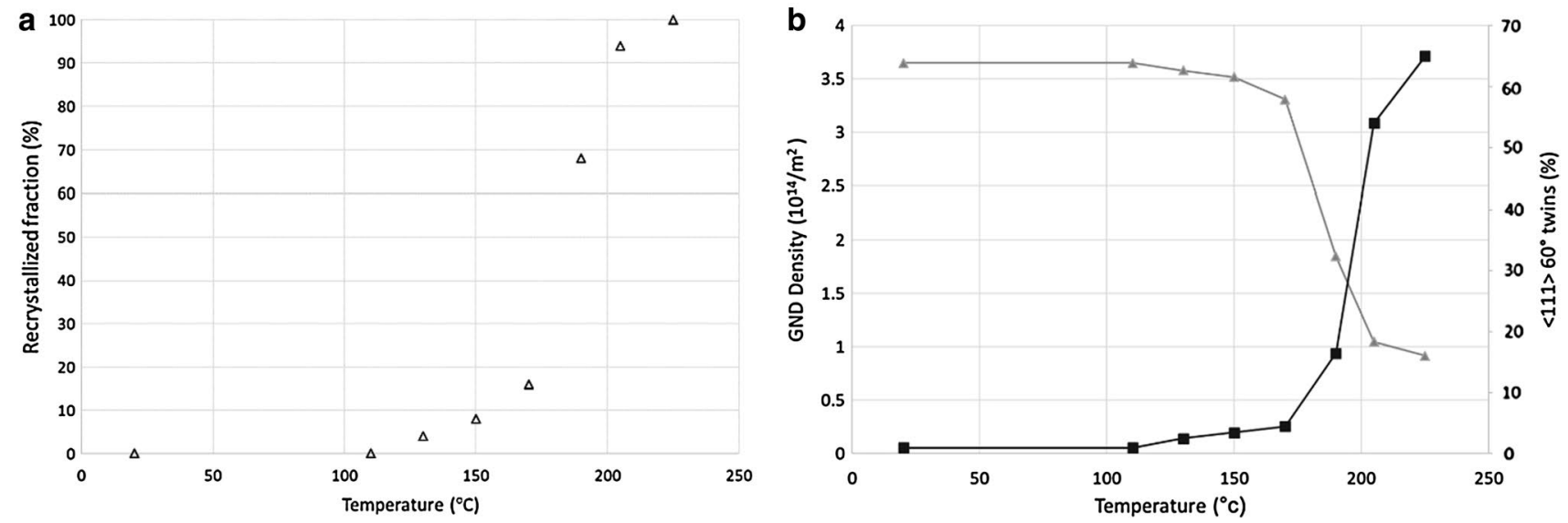

Fig. 5 a Recrystallized fraction of material versus temperature, b GND density decrease and $<111>60^{\circ}$ twins percentage increase versus temperature

a

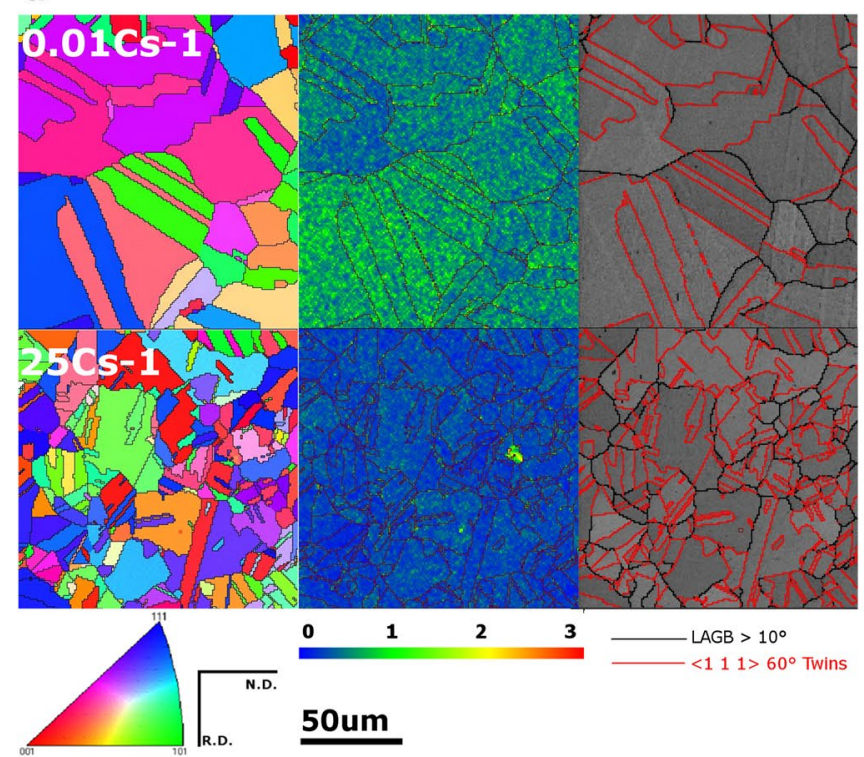

b

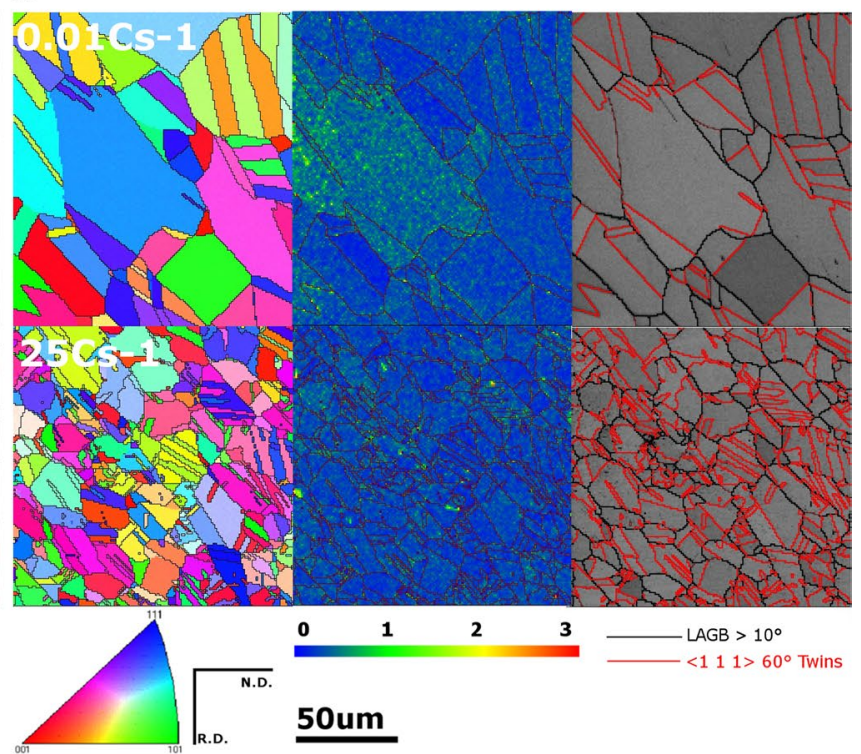

Fig. 6 a EBSD, local misorientation and grain boundary angle maps for non-deformed copper following heating to $500{ }^{\circ} \mathrm{C}$ at varied rates. b EBSD, local misorientation and grain boundary angle maps for strained copper following heating to $500{ }^{\circ} \mathrm{C}$ at varied rates

analysis of materials, samples from this study also showed close agreement with bulk analysis [20].

\section{Conclusions}

This study established the fact that strained Cu-dhp will recrystallize at much lower temperatures than expected due to the greater stored energy in dislocations driving polygonization of the material; evidence of recrystallization was evident at temperatures as low as $130^{\circ} \mathrm{C}$. Final grain size is heavily influenced by both initial condition; strained initial material yields a finer final microstructure; and heating rates, with faster heating leading to finer average grain sizes due to increased recrystallization kinetics. The presence of $\left\langle 111>60^{\circ}\right.$ grain twins appeared to be independent of heating rates, but have a slight dependence on initial condition with approximately $10 \%$ less grain twins in material that had initially undergone deformation.

Acknowledgements The key funding of this project as well as the supply of the materials was from Atomic Weapons Establishment (AWE) (Grant No. 1). In addition to that, the characterisation facility is supported from the Higher Education Funding Council for England 
(HEFCE) fund and the WMG Centre High Value Manufacturing Catapult is gratefully acknowledged.

\section{Compliance with Ethical Standards}

Conflict of interest The authors declare that they have no conflict of interests.

Open Access This article is distributed under the terms of the Creative Commons Attribution 4.0 International License (http://creativeco mmons.org/licenses/by/4.0/), which permits unrestricted use, distribution, and reproduction in any medium, provided you give appropriate credit to the original author(s) and the source, provide a link to the Creative Commons license, and indicate if changes were made.

\section{References}

1. J. Humphreys, M. Hatherly, in Recrystallization and Related Annealing Phenomena, ed. by F.J.H. Hatherly (Elsevier, Oxford, 2004)

2. R.D. Doherty, D.A. Hughes, F.J. Humphreys et al., Mater. Sci. Eng. A 238, 219 (1997)

3. F. Mandigo, J. Crane, in ASM Handbook, Volume 14: Forming and Forging, ed. by S.L. Semiatin (ASM International, Cleveland, 1998)

4. O. Engler, H.E. Vatne, E. Nes, Mater. Sci. Eng. A 205, 187 (1996)

5. M. Kumar, W.E. King, A.J. Schwartz, Acta Mater. 48, 2081 (2000)

6. S.G. Chowdhury, S. Das, B. Ravikumar, P.K. De, Metall. Mater. Trans. 37A, 2349 (2006)
7. V.Y. Gertsman, K. Tangri, R.Z. Valiev, Acta Mater. 42, 1785 (1994)

8. V.Y. Gertsman, C.H. Henager, Interface Sci. 11, 403 (2003)

9. O.V. Mishin, J. Mater. Sci. 33, 5137 (1998)

10. V.Y. Gertsman, K. Tangri, Z. Valiiev, Acta Metall. Mater. 42, 1785-1804 (1994)

11. S. Jakani, T. Baudin, C.H. de Novion, M.H. Mathon, Mater. Sci. Eng. A 456, 261 (2007)

12. T. Baudin, A.L. Etter, R. Penelle, Mater. Charact. 58, 947 (2007)

13. D.P. Field, L.T. Bradford, M.M. Nowell, T.M. Lillo, Acta Mater. 55, 4233 (2007)

14. F. Brisset, A. Helbert, T. Baudin, Microsc. Microanal. 19, 969 (2013)

15. L.N. Brewer, in Electron Backscatter Diffraction in Materials Science, 2nd edn., ed. by A.J. Shwartz, M. Kumar, B.L. Adams, D.P. Field (Springer, New York, 2009), p. 251

16. S. Taylor, V. Janik, R. Grimes, R. Dashwood, Mat und Werks 48, 876 (2017)

17. A. Nye, A.C. Leffa, C.M. Barra, M.L. Taheri, Scr. Mater. 146, 308 (2018)

18. M.M. Nowell, D.P. Field, S.I. Wright, T.M. Lillo, Mater. Sci. Forum 467, 1401 (2004)

19. D.P. Field, L.T. Bradford, M.M. Nowell, T.M. Lillo, Acta Mater. 55, 4233 (2007)

20. S. Clark, Y. Lan, V. Janik, Mater. Sci. Forum 879, 356 (2016)

Publisher's Note Springer Nature remains neutral with regard to jurisdictional claims in published maps and institutional affiliations. 